\title{
Building a Natural Earthquake Laboratory at Focal Depth (DAFSAM-NELSAM Project, South Africa)
}

\author{
by Ze'ev Reches and the DAFSAM and NELSAM teams
}

doi:10.2204/iodp.sd.3.06.2006

\section{Introduction}

The study of faulting and earthquake processes requires direct and near-field observations at the focal depth. Deep mines provide a unique opportunity to make such observations. The linked DAFSAM (Drilling Active Faults Laboratory in South African Mines)-NELSAM (Natural Earthquake Laboratory in South African Mines) projects focus on building an earthquake laboratory in deep gold mines in South Africa.

Gold is produced from the massive Precambrian sequence of the Witwatersrand basin by sub-horizontal mining at depths of $1.5-3.5 \mathrm{~km}$. During the lifetime of a mine, the gradual closure of the open space of the mine shafts and tunnels releases gravitational energy that induces intense seismic activity. Mine seismicity has been investigated extensively (e.g., McGarr et al, 1979; Mendecki, 1997), and mining-related earthquakes were found to resemble natural tectonic earthquakes in some ways but not in others (e.g., McGarr, 1999; Richardson and Jordan, 2002). Two types of mining-induced events have been recognized-those that are induced directly by mining operations (e.g., rock bursts) and those related to movements along major faults and dykes. The earthquake laboratory focuses on the second type, showing greatest potential for comparison with naturally occurring earthquakes.

Hundreds to thousands of small to moderate earthquakes per day are recorded in a typical deep mine; the strongest may reach an intensity of magnitude 5. Given that many of these earthquakes are controlled directly by the mining activity, their location, timing, and magnitude can be forecast, and instruments can be installed at sites where earthquakes of interest are predicted to occur. The mine infrastructure provides access to the earthquakes' source region and allows three-dimensional mapping of the fault zone. It also allows installation of a three-dimensional array of instruments 1-100 $\mathrm{m}$ from an anticipated hypocenter to monitor fault activity before, during, and after an earthquake. Most expected earthquakes exhibit a moment-magnitude range (-2 to 4$)$ that bridges the scale gap between laboratory experiments and tectonic earthquakes in the crust. The mine infrastructure provides an opportunity to investigate the effects of fracturing during earthquakes on fault fluid, gas chemistry, and microbiological communities. These promising conditions have led to the building of an earthquake laboratory in the TauTona gold mine in January 2005 as part of the DAFSAM-NELSAM project.

\section{The Laboratory Site at TauTona Mine}

The TauTona ("great lion" in Sotho) gold mine, the deepest mine on Earth, is located about $80 \mathrm{~km}$ west of Johannesburg within the Western Deep Levels of the Witwatersrand basin (Fig.1). The gold deposit is mined at $2-3.5 \mathrm{~km}$ depths, with a planned deepening to almost $4 \mathrm{~km}$ over the next decade. The deepening is facilitated by constructing two declined shafts that cut across the Pretorius fault (Fig. 2), the largest fault in the western deep area of the mine. We chose the section of the Pretorius fault that intersects the two declined shafts as the most promising site for the DAFSAM-NELSAM earthquake laboratory (Fig. 2). The fault cuts across the slightly metamorphosed Precambrian sedimentary rocks of the Witwatersrand basin, mainly quartzite, conglomerates, and mudrocks, as well as basaltic bodies. The region has been 
tectonically inactive for the last $2.5 \mathrm{Ga}$. The Pretorius fault is at least $10 \mathrm{~km}$ long, trending east-northeast, with a vertical throw of 30-60 $\mathrm{m}$ and an estimated right-lateral displacement up to $200 \mathrm{~m}$. It has a 25-30-m-wide fault zone with tens of anastomosing segments, dominantly dipping north and south (Fig. 3). The majority of these segments dip steeply $\left(40^{\circ}-90^{\circ}\right)$, with some branches into bedding planes that dip $20^{\circ}-22^{\circ}$. Many of the individual segments of the Pretorius fault display zones of sintered gouge (cataclasites) with a thickness up to tens of centimeters (lower left in Fig. 3). The cataclasite consists of a green to gray, fine-grained quartzitic matrix with quartz clasts up to the decimeter scale, and it displays structural evidence for granular flow and local melting.

\section{Building the Laboratory}

Our laboratory operations in the TauTona mine this year have focused on the following key items.

1. Drilling through the Pretorius fault zone. A cubby was established within the Pretorius fault zone (Site 8 in Fig. 2A) at a depth of $3.54 \mathrm{~km}$. We drilled five boreholes, all gently inclined and ranging from $17^{\circ}$ downward to $25^{\circ}$ upward and from 20 to $60 \mathrm{~m}$ in length (Fig. 3). One borehole will host an Ishii strain meter. Two boreholes (DAF1 and DAF2, Fig. 3) form a colinear 95-m-long borehole for installing a creep meter. This creep meter will be anchored across the entire fault zone to detect its slip in a wide dynamic range. A fourth borehole (DAFBIO) will be used for in situ experiments on microbiological activity, and a fifth borehole (DAFGAS) will be used for continuous monitoring of faultzone gases.

A
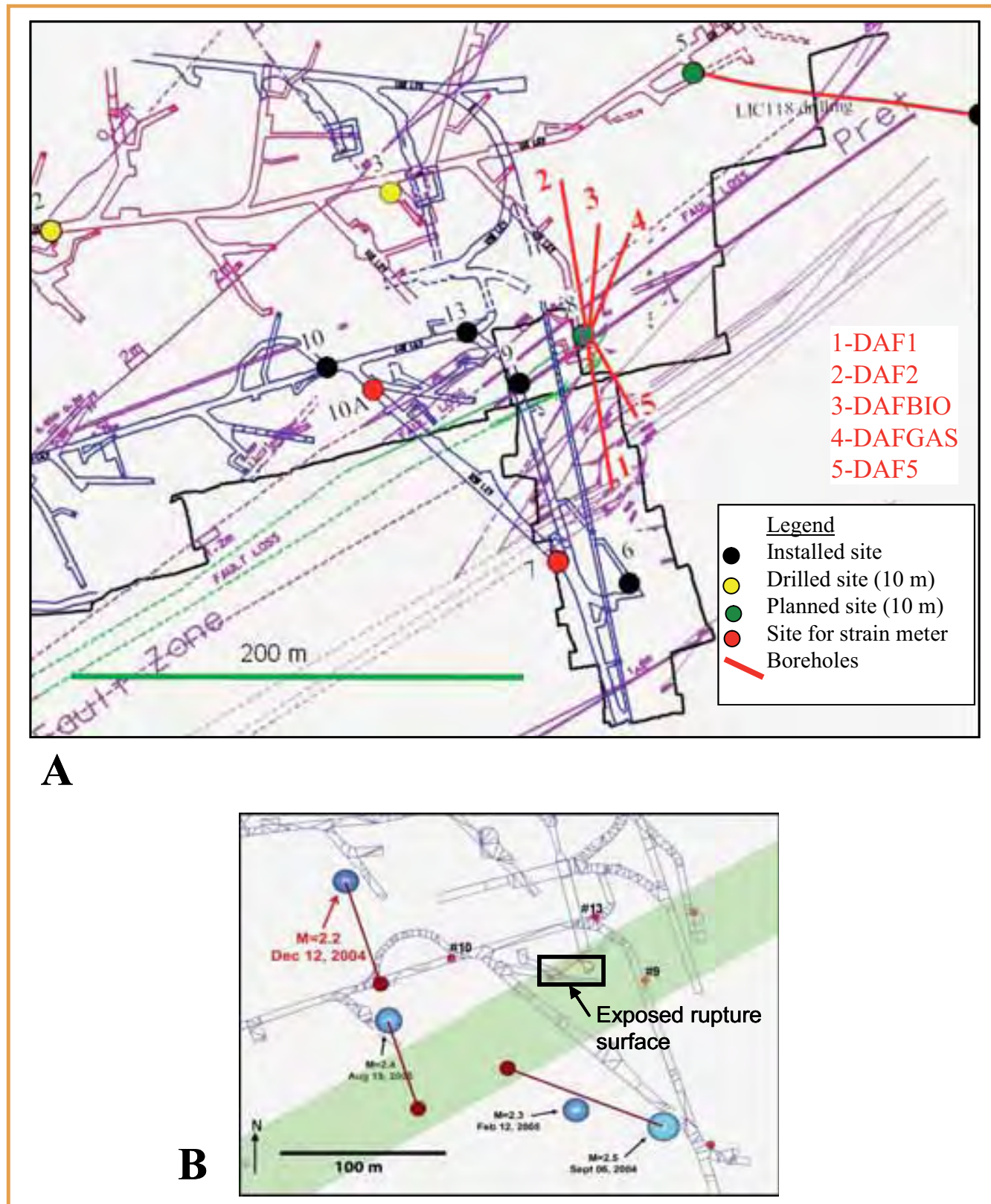

Figure 2 [A] Earthquake laboratory at levels 118-120 of TauTona mine. Tunnels at level 118 (depth = $3.54 \mathrm{~km}$ ) are marked by red lines; tunnels at level 120 (depth = $3.6 \mathrm{~km}$ ) are marked by blue lines; wide zone in light green is Pretorius fault zone; thick black line marks margins of mining on both sides of Pretorius fault. Note that while only a small part south of fault has been mined, this part will be mined in next decade; sites marked 2-10 indicate sites of installed or planned system of two 3-D accelerometers, EM sensors and thermistors; Site 8 is laboratory cubby with five inclined boreholes (Fig. 3). [B] Locations of $m>2$ events near the laboratory. Original locations marked in light blue circles; preliminary relocations are marked by brown solid circles connected to original location. Note that relocation moves events closer to Pretorius fault.

2. Site characterization. We have characterized the earthquake laboratory site by three-dimensional structural mapping of the ancient Pretorius fault zone and fault segments that were reactivated during recent earthquakes. Five boreholes were logged with a borehole camera for in situ stress analysis. Mechanical and chemical laboratory testing will be conducted on samples of rock, gouge, and fluid from the Pretorius fault, as well as on the microbial properties of the cores from the fault zones and adjacent country rock. 


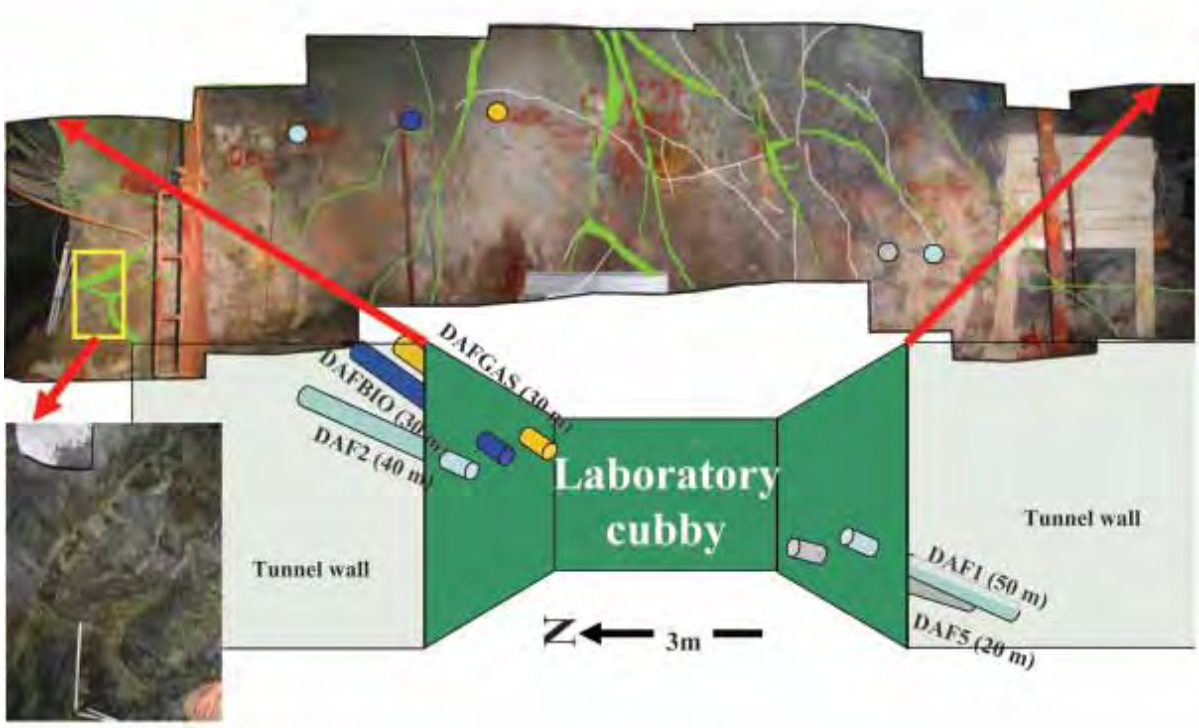

Figure 3. Three-dimensional view into laboratory cubby within Pretorius fault zone in level 118 (site 8 , Fig. 2A). Panoramic composite photo (above) displays segments of Pretorius fault filled with sintered cataclasite (light green with detail on lower left). Heads of five boreholes are marked in various colors that correspond to their 3-D presentation in schematic view below.

3. An instrument array (Fig. 2A). When completed by the end of 2006, the laboratory will include a dense array (250- $\mathrm{m}^{2}$ footprint) of accelerometers (3-D broadband, up to $15 \mathrm{~g}$ ), seismometers, strain meters, temperature sensors, creep meters, electromagnetic radiation system, and acoustic emissions. Fault-zone fluid chemistry will be monitored with an on-site mass spectrometer after 2006.

\section{Earthquakes and Rupture Zones Along the Pretorius Fault}

The network of TauTona mine tunnels was used for threedimensional mapping of the rupture zone associated with the 2004 earthquake of magnitude 2.2. Mapping was conducted in three interconnected tunnels, one of which was made after the event, and the rupture was traced to a horizontal distance of $40 \mathrm{~m}$ (minimum length). Along its entire trace the rupture reactivated three segments of the ancient Pretorius fault (Fig. 4). These segments are quasi-planar, crosscutting segments within the fault zone that carry sintered, metamorphosed Archaean gouge. The reactivated segments strike in east-northeast directions, yet their inclination varies from $21^{\circ}$ (a bedding surface) to $90^{\circ}$. Two displaced rock-bolts (Fig. 4C) reveal $10 \mathrm{~mm}$ and $25 \mathrm{~mm}$ of normal-dextral slip with rake of $23^{\circ}$ and $35^{\circ}$, respectively. The rupturing formed fresh, fine-grained, white rock powder almost exclusively along the contacts of the sintered cataclasite and the quartzitic host rock (Fig. 4A). This rock powder is commonly observed in brittle failure in South African mines, and here it appears in one to five thin zones that are each $0.5-1.0 \mathrm{~mm}$ thick. Locally, the rupture zone is accompanied by a set of vertical, secondary tensile fractures in the hanging wall (Fig. 4B).

\section{In Situ Stress Field}

The bedrock encountered in the TauTona mine is the highly competent quartzites of the Witwatersrand group (uniaxial strength exceeding $200 \mathrm{MPa}$ and Young modulus exceeding $80 \mathrm{GPa})$. In situ stress was determined by analysis of borehole breakouts and drilling induced tensile fractures using images collected with a borehole camera. A slimhole, 48-mm optical borehole camera (Robertson Geologging) was used to $\log$ three vertical boreholes, each $\sim 10$ m deep (marked 9, 10, 13, in Fig. 2A, 2B), and two inclined holes, one 418-m-long at $10^{\circ}-15^{\circ}$ inclination (red 5, Fig. 2A) and one 37-m-long at $19^{\circ}$ inclination (labeled DAF1, Fig. 2A). It is likely that the $418-\mathrm{m}$-long hole reflects primarily the ambient, undisturbed tectonic stress, whereas the shorter

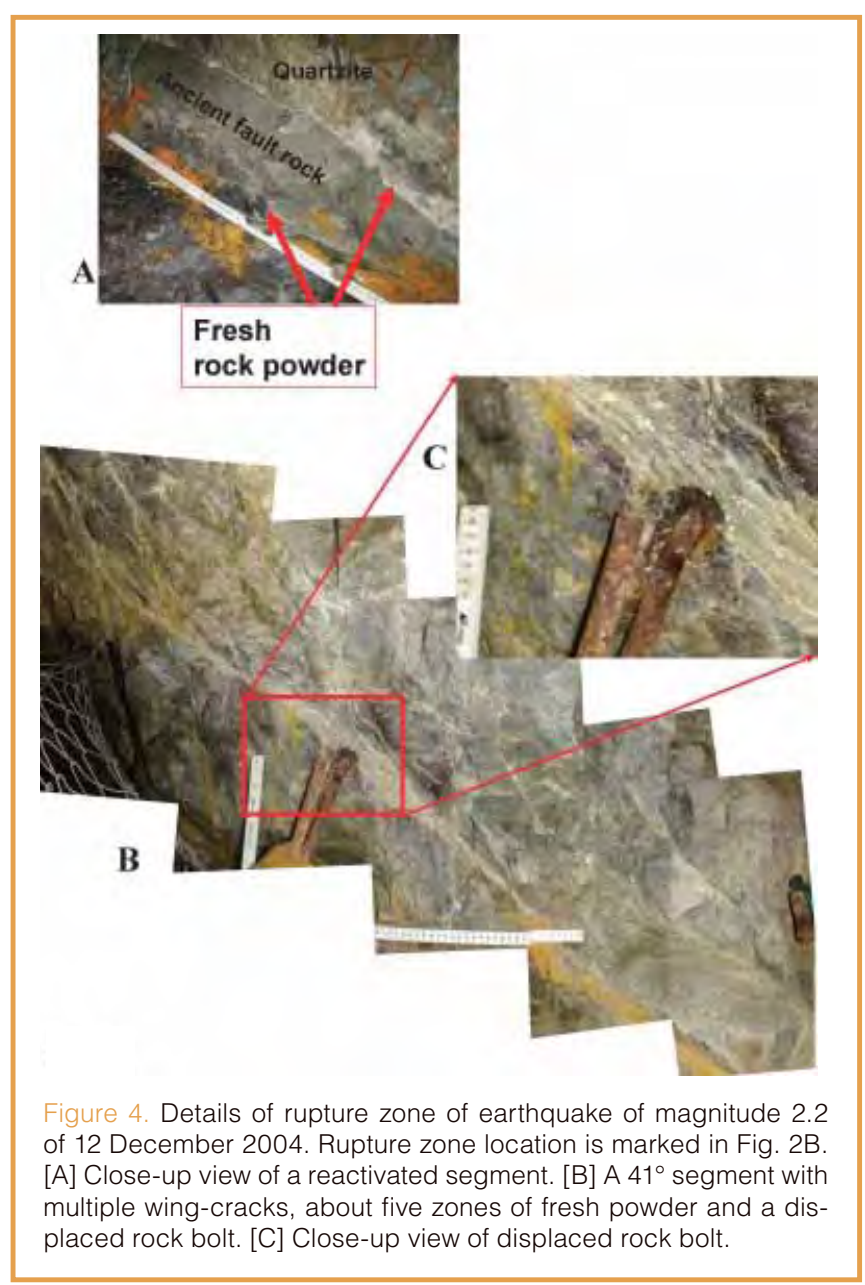




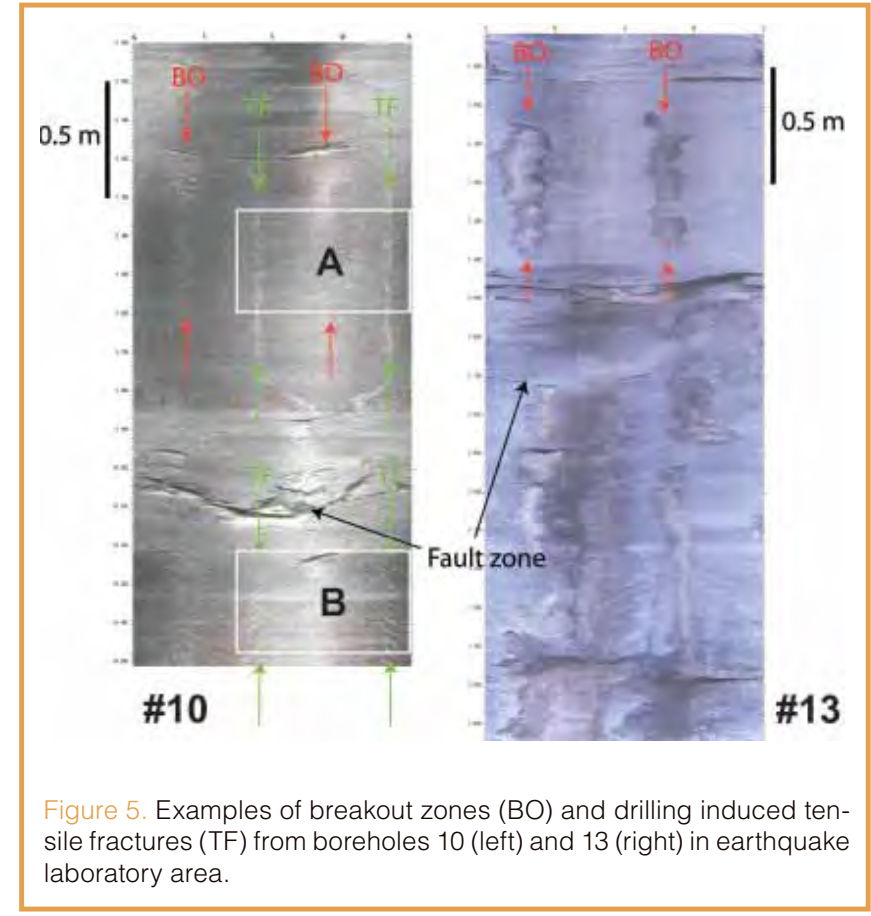

holes are strongly affected by stresses induced by the mine infrastructure.

The three short, vertical boreholes lie within the area of the earthquake laboratory (Fig. 2), less than $70 \mathrm{~m}$ from the reactivated rupture zone. The images from these boreholes display several zones of breakouts and drilling-induced fractures (Fig. 5). The long borehole (LIC118 hole in Fig. 2) penetrates away from current mining activity. Breakouts were observed for almost the entire logged portion of $418 \mathrm{~m}$, yet no tensile fractures were observed. Four trends of breakouts were detected, and two of them coincide with the location of the Pretorius fault zone.

\section{Anticipated Contributions}

Given to the expected proximity of our 3-D dense instrument array to the hypocenters of future earthquakes, the observations to be made during the DAFSAM-NELSAM project are expected to contribute key data on:

- The scales and processes of nucleation, eventual size of the ensuing dynamic rupture, and additional preceding signatures (e.g., geochemical and electromagnetic anomalies, cascading events).

- The detailed properties, dynamics, and energetics of the rupture process (velocity, geometry, crack vs. pulse mode of rupture, dynamic versus geometric sources of heterogeneity, possible opening motion).

- The orientations, magnitude, and heterogeneity of the stress and strain fields in the vicinity of an active fault, and their variations during seismically active and calm periods.

- The Structural, mechanical, and geochemical features related to active fault zones and rupture zones, and their relations to the seismic observations.
- The effects of faulting and earthquakes on the microbiological activity in the fault zone. Do active fault zones host unique communities? Do seismic events increase the microbiological activity or its diversity?

In addition new educational opportunities for American and South African students to improve their understanding of tectonics and structural geologic processes through handson involvement with fault-zone mechanics are provided.

\section{Acknowledgements}

The DAFSAM-NELSAM project is an international collaboration of dozens researchers from several institutes including University of Oklahoma, U.S. Geological Survey, University of Southern California, Stanford University, Princeton University, ISSI Ltd., TauTona Mine, University of Free State, Council for Scientific and Industrial Research South Africa (CSIR), GeoForschungsZentrum Potsdam, Germany, and Ritsumeikan University, Japan. The TauTona Mine collaborated logistically and financially with DAFSAM in building the earthquake laboratory. Many thanks to the people of AngloGoldAshanti in TauTona mine for their invaluable hospitality and support as well as to Hiroshi Ogasawara of Ritsumeikan University for the collaboration drilling DAF5.

This work was supported by the U.S. National Science Foundation (NSF) under Grant \# 0409605. Any opinions, findings and conclusions or recommendations expressed in this work are those of the authors and do not necessarily reflect the views of NSF.

\section{References}

McGarr, A., 1999. On relating apparent stress to the stress causing earthquake fault slip. J. Geophys. Res., 104:3003-3011, doi:10.1029/1998JB900083.

McGarr, A., Spottiswoode, S.M., Gay, N.C., and Ortlepp, W.D., 1979. Observations relevant to seismic driving stress, stress drop, and efficiency. J. Geophys. Res., 84:2251-2261.

Mendecki, A., 1997. Seismic Monitoring in Mines. London, UK (Chapman and Hall).

Richardson, E., and Jordan, T.J., 2002. Seismicity in deep gold mines of South Africa: Implications for tectonic earthquakes. Bull. Seism. Soc. Amer., 92:1766-1782, doi:10.1785/0120000226.

\section{Authors}

Ze'ev Reches, School of Geology and Geophysics, University of Oklahoma, Norman, Okla. 73019, U.S.A., e-mail: reches@ ou.edu.

\section{and the DAFSAM and NELSAM teams}

\section{Related Web Links}

http://earthquakes.ou.edu/

http://witwaters.icdp-online.org/ 